\title{
A hydrogeological investigation using EM34 and SP surveys
}

\author{
Fernando A. Monteiro Santos ${ }^{1}$, Eugénio P. Almeida ${ }^{1,2}$, R. Castro ${ }^{1}$, R. Nolasco ${ }^{1}$, and Luís Mendes-Victor ${ }^{1}$ \\ ${ }^{1}$ Departamento de Física and Centro de Geofisica da Universidade de Lisboa, Edíficio C8, Piso 6, Campo Grande, $1749-016$ Lisboa, Portugal \\ ${ }^{2}$ Instituto Politécnico de Tomar, 2300 Tomar, Portugal
}

(Received December 11, 2000; Revised October 2, 2001; Accepted December 6, 2001)

\begin{abstract}
EM34 and SP surveys were used to delineate shallow structures associated with the mineral water springs in the Vilarelho da Raia area located NE Portugal. This spring is part of a set of $\mathrm{CO}_{2}$-rich mineral (hot and cold) waters connected to the main Hercynian NNE-SSW fault systems. The EM34 survey was interpreted using a quasithree-dimensional inversion approach based on a smooth-regularisation algorithm. The model put into evidence the conductive overburden as well as the fractured granitic formation. A preliminary estimation of the aquifer porosity is made based on the EM34 model. The SP anomalies were interpreted considering as having their sources on the aquifer interfaces. The modelling of two SP profiles allow the characterisation of a fault connected to the spring.
\end{abstract}

\section{Introduction}

Along the megalineament of Verin-Chaves-Penacova (northern Portugal, see Fig. 1), numerous emanations of hot (Chaves) and cold (Vilarelho da Raia, Vidago and Pedras Salgadas) $\mathrm{CO}_{2}$-rich mineral waters can be found. These thermomineral waters flow from natural springs and most of them are used in local spas since Roman times.

A special attention has been put on the characterisation of the local low-temperature geothermal resources (AiresBarros et al., 1995, 1998; Monteiro Santos et al., 1995, 1996). The results obtained indicated that the chemical and isotopic composition of Vilarelho da Raia cold $\mathrm{CO}_{2}$ rich mineral waters is similar to that of Chaves hot $\mathrm{CO}_{2}$-rich mineral waters. The lower temperature $\left(17^{\circ} \mathrm{C}\right)$ and flow rate (2.5 $1 / \mathrm{min})$ of the Vilarelho da Raia springs, together with the lower tritium activity, pointed to a longer circulation time from the recharge area to the surface (Marques et al., 2000).

Due to the commercial interest of that spring, some multidisciplinary experiments were designed to draw the conceptual model of the local and regional underground circulation associated with the Vilarelho da Raia cold $\mathrm{CO}_{2}$-rich mineral waters. Geochemical, isotopic and geophysical studies have been adopted to distinguish recharge regions and pathways of fluids emerging in the region. In this paper the results concerning the geophysical surveys (electromagnetic and self-potential) carried out with the objective to characterise fault zones and related water shallow circulation, in the Vilarelho da Raia area, are presented. The paper shows the complementary aspects of those techniques in hydrogeological problems.

Copy right (C) The Society of Geomagnetism and Earth, Planetary and Space Sciences (SGEPSS); The Seismological Society of Japan; The Volcanological Society of Japan; The Geodetic Society of Japan; The Japanese Society for Planetary Sciences.

\section{Geological Sketch}

The Vilarelho da Raia-Chaves region (Fig. 1) is part of a major hydrogeological province where the upflow of thermomineral waters are structurally controlled by the fault systems associated with the NNE-SSW megafault extending from Verin (Spain) to Penacova (central Portugal). The geomorphology of that province is dominated by several tectonic depressions. The "Chaves basin" and "Vilarelho da Raia basin" are grabens whose axes are roughly oriented NNE-SSW. They are bounded at the east side by the edge of Padrela Mountain showing an escarpment with a $400 \mathrm{~m}$ throw in Chaves region. In the NW part of Vilarelho da Raia area, the geomorphology is controlled by the Larouco Mountain (1500 $\mathrm{m}$ a.s.1.) whose edge is oriented NNE-SSW.

The region is located in the Ante-Mesozoic Iberian Massif that consists mainly of Hercynian granites and Palaeozoic metasediments (Portugal Ferreira et al., 1992). The oldest formations correspond to the Schisto-Graywacke Complex (Ante-Ordovician). At Ordovician and Silurian times quartzites and schists were formed, being metamorphosed at the end of Palaeozoic by the Hercynian granitic intrusions. The Vilarelho da Raia and Chaves granites have been classified into the alkaline granites of the 3rd Hercynian phase (310 My). The Silurian metamorphic formations have been recognised in both easternwards and westernwards sides of the Chaves basin. The most recent formations are MiocenePleistocene sedimentary series (lacustrine, alluvial, detritic, etc.). These formations show variable thickness along the basins. Extensive neo-tectonic features were originated by Alpine Orogeny. These events were responsible for the formation of several low-entalphy hydrothermal fields.

\section{Electromagnetic Survey \\ 3.1 EM34 data}

The EM34-3 system consists of two coils: one is the transmitter and the other one is the receiver. The transmitter is energised with an alternating current at a specific fre- 


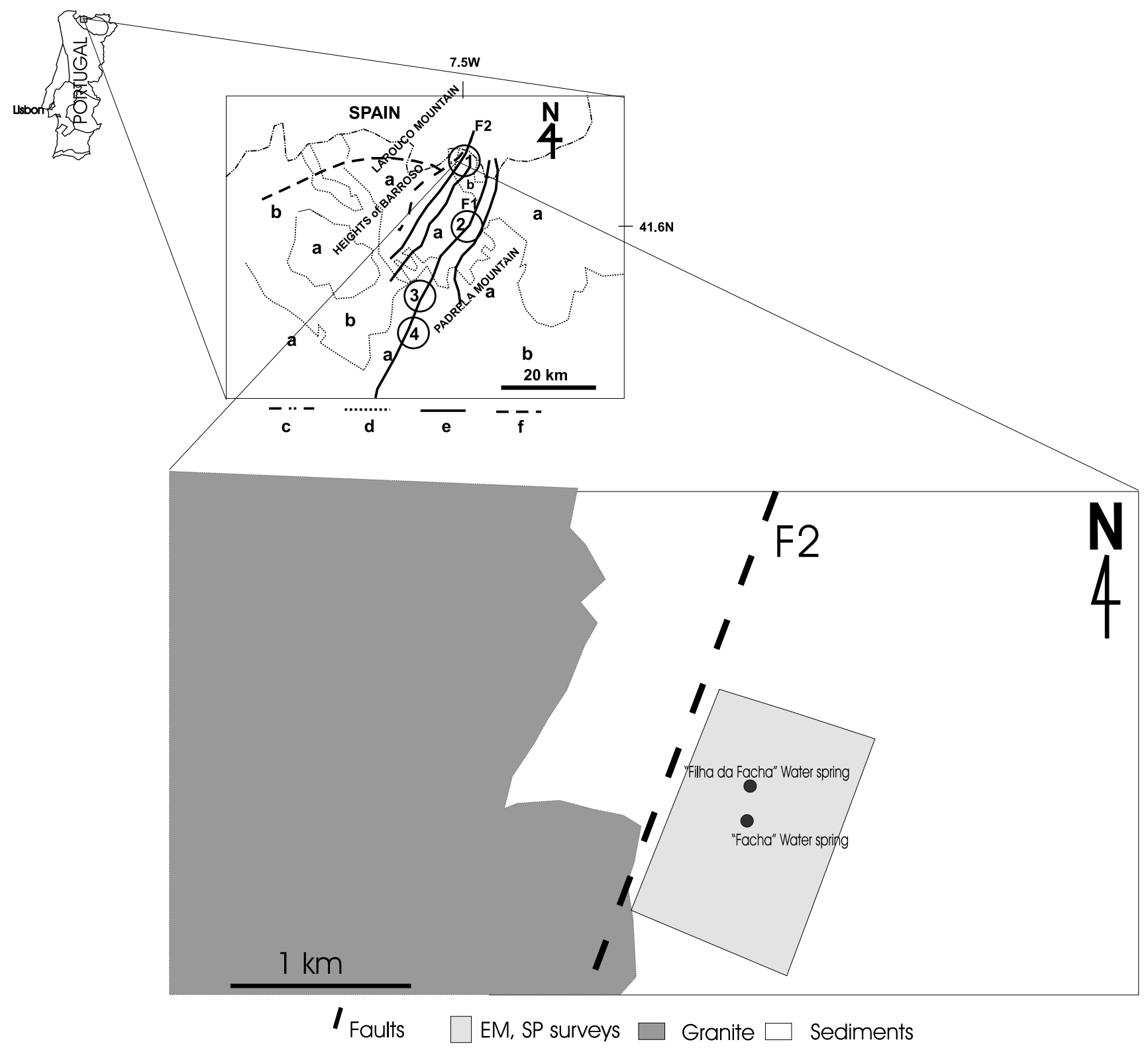

Fig. 1. General view of the NE Portugal and location of the surveys. F1-Chaves-Verin fault; F2-Vilarelho da Raia fault; a-Granitic formations; b-Metasediments; c-Portugal-Spain boundary; d-geologic limits; e-fault; f-fault probable. Springs: 1-Vilarelho da Raia; 2-Chaves; 3-Vidago and 4-Pedras Salgadas.

quency. Usually three frequencies are used seeking for different investigation depths. The primary magnetic field generated from the transmitter induces current in the subsurface. These currents generate a secondary magnetic field, which is detected, together with the primary field, by the receiver coil (see, e.g., McNeill, 1990). There are two main modes of operation: in the first mode (horizontal dipole mode, HDM) both coils, the transmitter and receiver, are located vertically; in the second mode (vertical dipole mode, VDM) the coils lie horizontally, on the surface.

Electromagnetic profiles (using the EM34-3 equipment) were carried out around the Vilarelho da Raia spring (in an area of approximately $2 \mathrm{~km}^{2}$ ) to outline shallow conductive structures probably connected with local water circulation. The results of such a study are also important in the future delimitation of a protected zone from contamination. In fact, zones around the natural spas are used for agricultural activities and cattle-raising. It's well known that pollutants generated from these activities are mainly transported through surface water. It is then very important to protect the aquifer from those waters. The most efficient and economical way to do that is to make use of the natural overburden (when present) in order to reduce or eliminate the transport of pollutes through the aquifer. Therefore, characteristics of the overburden are important and were one of the goals of the work presented in this paper.

The data was acquired along eight north-south profiles with an intercoil spacing of $40 \mathrm{~m}$. The distance between measurement points was also $40 \mathrm{~m}$. At each site two measurements were made using both, horizontal and vertical 


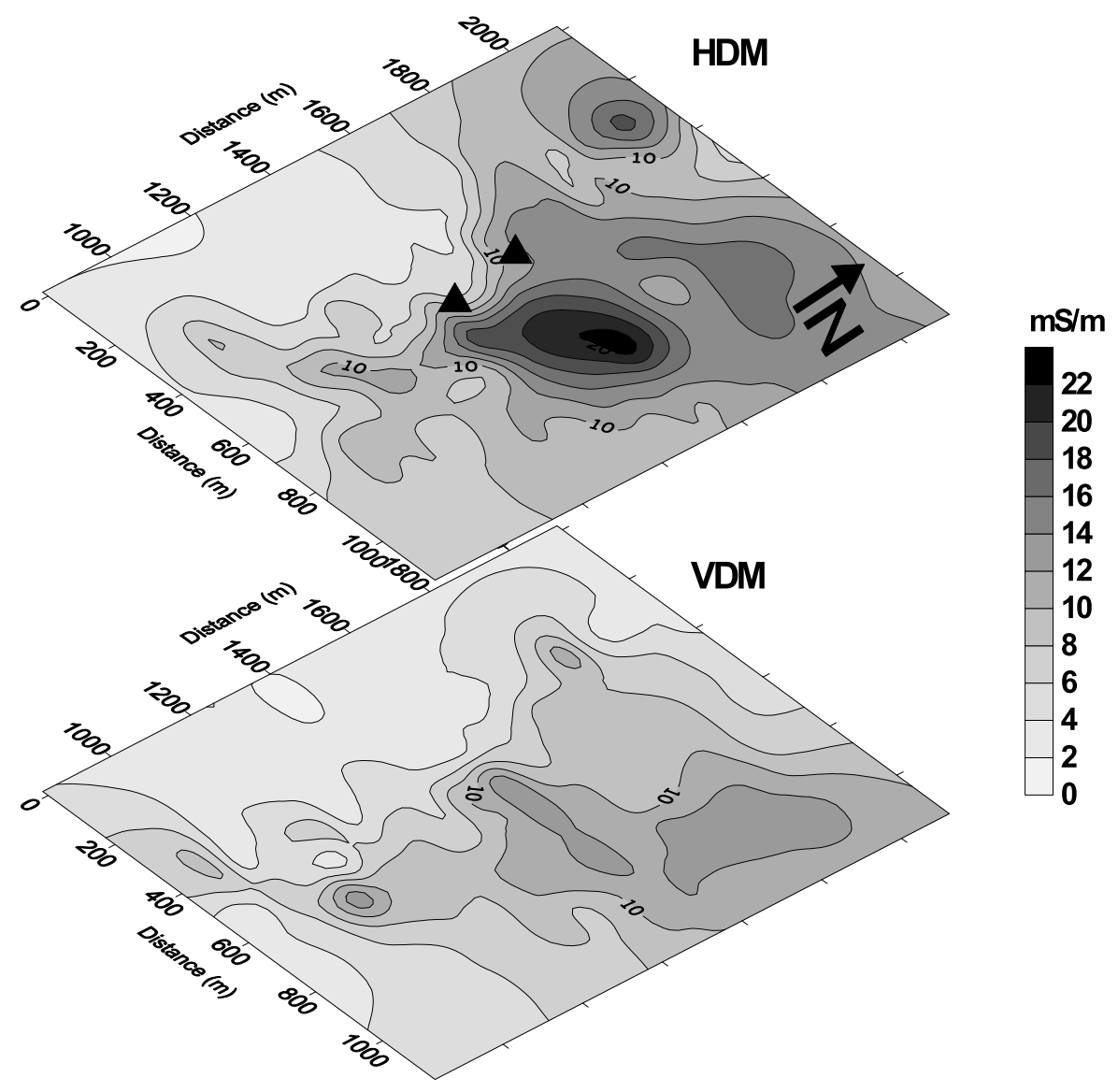

Fig. 2. EM34 field data from horizontal and vertical dipole mode (HDM and VDM, respectively). The location of the water springs is marked by triangles.

dipole mode. The topography of the surveyed area is flat at a level of $350 \mathrm{~m}$.

The measured conductivity maps for vertical and horizontal coils are shown in Fig. 2. Taking into account the used intercoil spacing the data reveals the influence of the structures lying in the uppermost part of the subsurface (50$60 \mathrm{~m}$ ). A more conductive NE overburden is revealed by the surveys. The main conductivity contrasts, roughly W-E to NW-SE oriented, were interpreted as the shallow expression of faults affecting the sedimentary filling of the basin.

\subsection{Interpretation}

Usually the interpretation of the EM34-3 data is qualitative. One-dimensional modelling or inversion is, however, possible. In this paper a quasi-three-dimensional inversion of EM34-3 data was used (Monteiro Santos et al., 2001). A mesh of prismatic blocks centred at each measurement point, as is usual in three-dimensional modelling, make up the earth model. The program inverts all the data set jointly, using the cumulative response (see McNeill, 1980) approach at each site of the grid of measurements to calculate the forward response and derivatives. Spatial smoothness constraints are introduced during the inversion procedure in order to construct a conductivity model, which represents the main features contained in the data (Sasaki, 1989).

The least square solution of such a non-linear smoothing problem is:

$$
\delta \mathbf{p}=\left(\mathbf{J}^{T} \mathbf{J}+\lambda \mathbf{C}^{T} \mathbf{C}\right)^{-1} \mathbf{J}^{T}(\mathbf{d}-\mathbf{y}) .
$$

Here $\mathbf{p}$ is the vector containing model parameters, $\mathbf{y}$ is the vector containing the response of the model (apparent conductivity), $\mathbf{d}$ represents the observed data set and $\mathbf{J}$ is the sensitivity matrix. The elements of the matrix $\mathbf{C}$ are the coefficients of the approximate value of the roughness in each model block (see, e.g. Sasaki, 1989 for details).

Although the final result obtained applying such a method is only a rough approach of a three-dimensional model and, for this reason it is designated as quasi-three-dimensional model, it can be very useful in the global interpretation of surveys.

From the field data, two input grids $(12 \times 27$ points $)$ were generated using a kriging algorithm. The final model $(972$ blocks) is shown in Fig. 3 as horizontal slices at depths of 10 , 20 and $40 \mathrm{~m}$. The responses of the quasi-three-dimensional model are shown in Figs. 4(a) and (b). The final fit, between field and calculated data is quite good, taking into account the approaches used. The conductivity distribution obtained shows relative high-conductivity zones (15 to 20 $\mathrm{mS} / \mathrm{m}$ ) in an almost uniform medium with conductivity less than $9 \mathrm{mS} / \mathrm{m}$. The overburden is more conductive in the NE part of the survey. This area corresponds to clay-rich sediments with significant water content. In depth, the conductive features are mainly concentrated around the spa zone. It is not possible, however, to correlate directly the pattern of the conductive zones with known or probable faults. There is only a slight indication of an E-W preferential direction of the conductive zone in the spa area. 

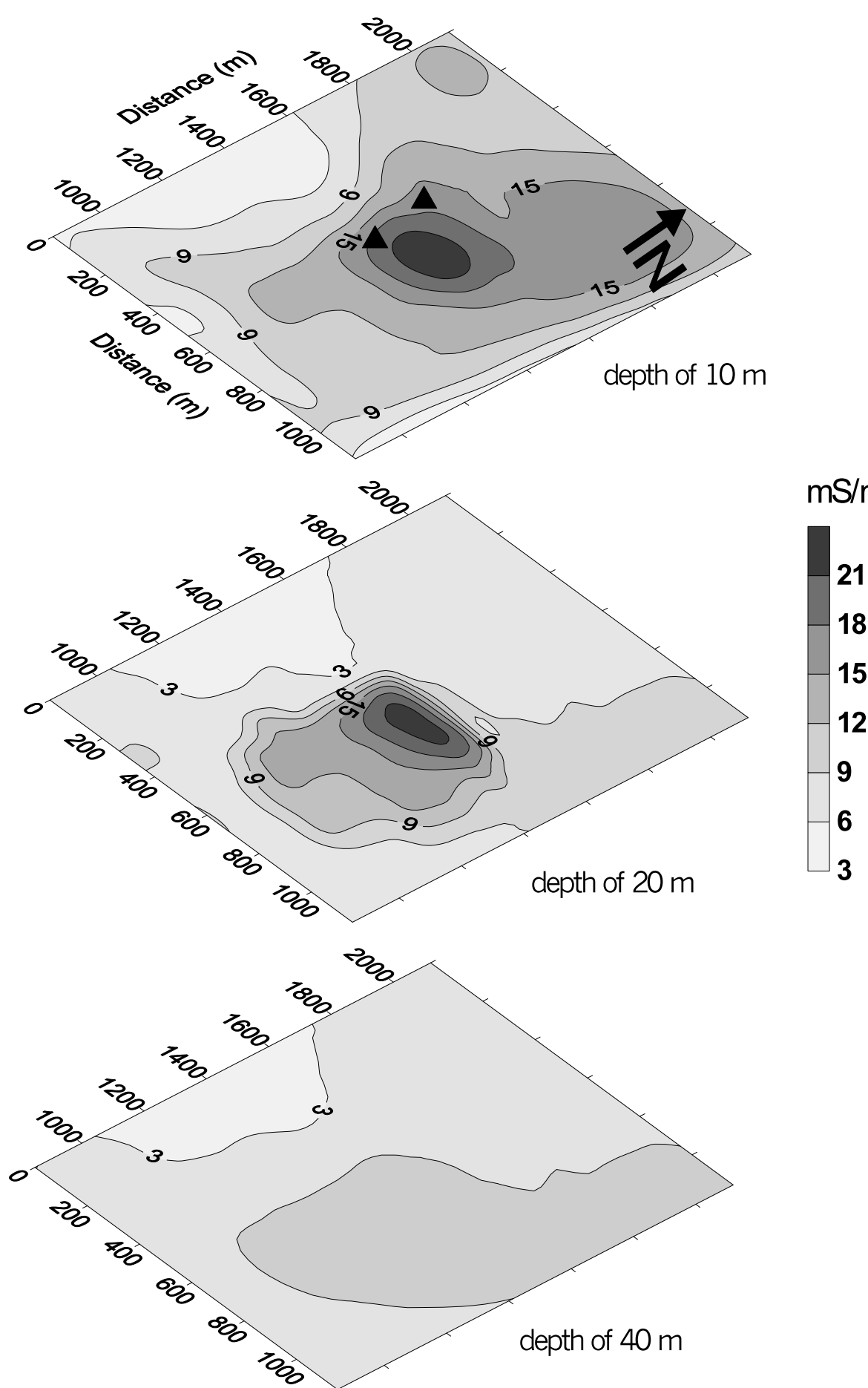

Fig. 3. Horizontal slices (at depths of $z=10,20$ and $40 \mathrm{~m}$ ) of the quasi-three-dimensional model obtained from EM34 data inversion.

In terms of aquifer protection it must be noted that the aquifer is not well protected except in the NE area. In fact, the overburden is thin in the major part of the surveyed area and the electrical conductivity of the zones corresponding to the granite formation ( $7 \mathrm{mS} / \mathrm{m}$ in average) indicates that this is a very fractured massif. Applying the Archie's law (with an exponential of -2.35 , for fractured media (Astier, 1982), and a water resistivity of $4 \mathrm{ohm} \mathrm{m}$ (Marques et al., 2000) a porosity of $20 \%$ is estimated for the granite.

\section{Self-Potential Survey}

\subsection{SP data}

The self-potential method (SP) is based on measurements of the steady state and natural potentials existing on the ground surface. There are several mechanisms that can generate such potentials: thermoelectric, electrokinetics and electrochemical. Among these mechanisms, electrokinetics is the most probable in the Vilarelho da Raia zone. Taking this in consideration the magnitude and the distribution of the SP potential at surface can provide useful information of 


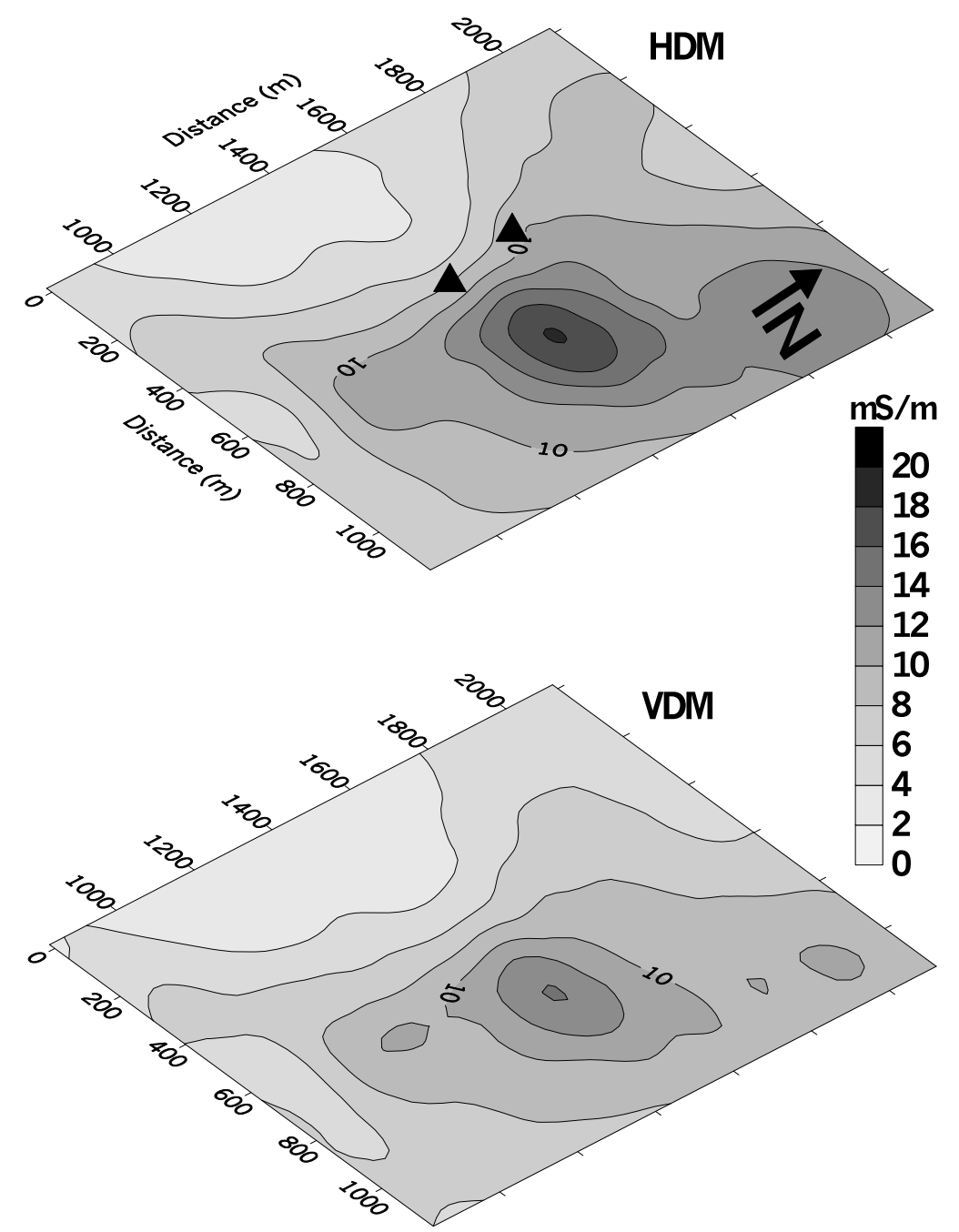

Fig. 4(a). HDM and VDM model response of the model shown in Fig. 3.

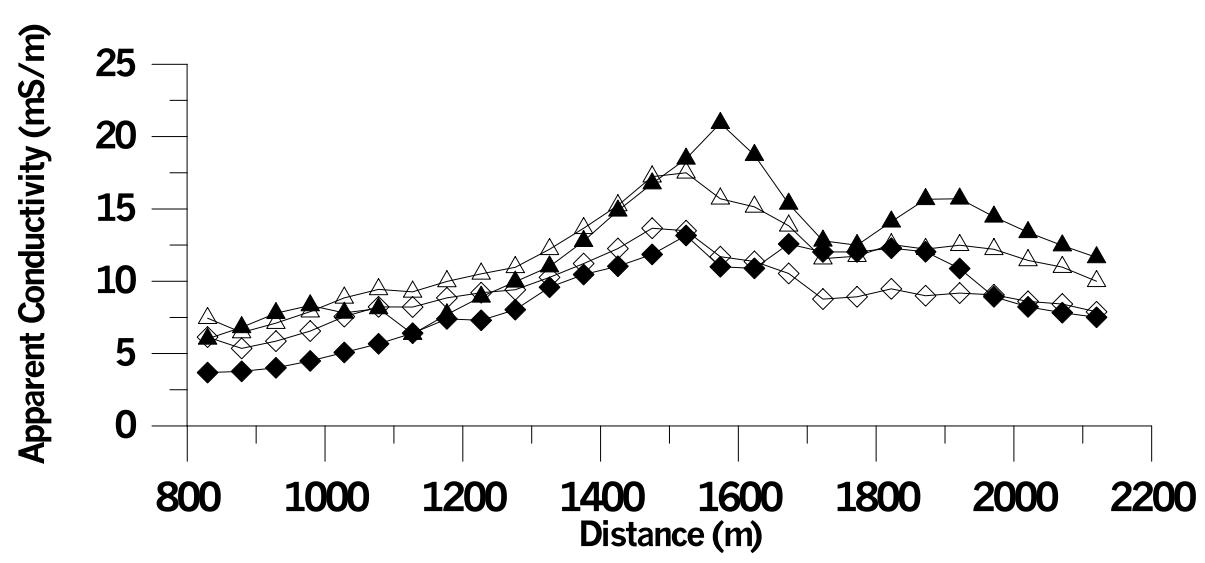

Fig. 4(b). Comparison between HDM (solid triangles) and VDM-data (solid diamonds) and model responses (open symbols) for one profile crossing the anomalous zone in N-S direction (at the E-W co-ordinate of $830 \mathrm{~m}$ ).

the underground flows. The SP surveys were carried out in two different times: in March and in May of 1999. The two SP areal surveys are displayed in Fig. 5. The SP measurements were made accordingly to the gradient method, alternating the leading and following electrodes in order to can- cel the electrode polarisation every two field measurements. The measurement sampling interval was $50 \mathrm{~m}$. $\mathrm{Pb}-\mathrm{PbCl}_{2}$ electrodes have been used in association with a digital voltmeter with 1 Gohm input impedance. One of the measured points (marked A in Fig. 5) was used as reference (poten- 

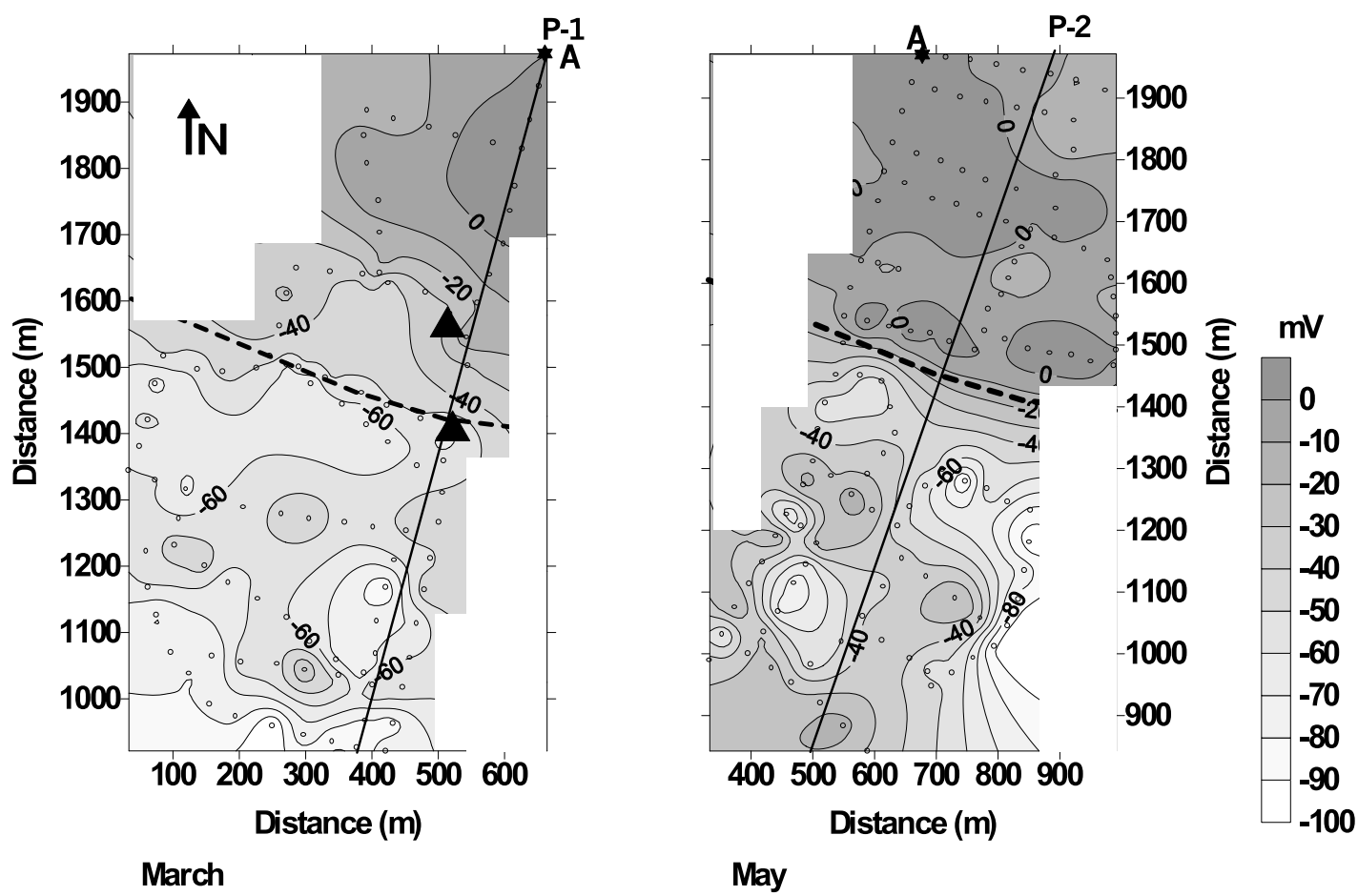

Fig. 5. Self-potential map around the natural springs (Facha and Filha da Facha). Small circles represent the measuring points; A is reference point chosen for SP; dashed line represents probable fault; P-1 and P-2 are the location of two SP profiles; triangles-water springs.

tial equal to zero). Thus all the points have been attributed a potential value with respect to $A$.

Although time variations of the SP anomalies (ascribe to variable weather conditions) are detected in the southern part, a clear pattern is observed: a roughly E-W oriented $\mathrm{SP}$ gradient can be noted. This feature can be related to electrokinetics phenomena occurring along a NWW-SEE to E-W fault.

\subsection{Interpretation}

Following Fournier (1989), the SP anomalies were considered as having their source on the aquifer interfaces. The theoretical bases of the modelling method are fully explained in the paper by Fournier (1989). Therefore, we only refer the main lines of the fundaments of the method. According to Fitterman (1978), in a steady state regime, the density of current $\mathbf{j}$ can be defined as the sum of a conductive current and a convective current:

$$
\mathbf{j}=-\sigma(\nabla V+C \nabla H)
$$

$\sigma$ is the electric conductivity, $\nabla V$ is the electric field vector, $\nabla H$ the hydraulic gradient and $C$ the electrokinetics coupling coefficient. Assuming that the ground can be divided into several zones of homogeneous properties and no current source except electrokinetics phenomena, we have (Fournier, 1989):

$$
\begin{aligned}
& \operatorname{div} \mathbf{j}=0 \\
& \mathbf{j}=-\sigma \operatorname{grad} \psi \\
& \psi=V+C H
\end{aligned}
$$

where $\psi$ represents the total electric potential. Through the interface between two homogeneous zones the conductivity and the coupling coefficients can change, but $V, H$ and the normal component of the total current are continuous, i.e.,

$$
\begin{aligned}
\sigma_{1} \frac{\partial \psi_{1}}{\partial n} & =\sigma_{2} \frac{\partial \psi_{2}}{\partial n} \\
\psi_{2}-\psi_{1} & =-\left(C_{2}-C_{1}\right) H .
\end{aligned}
$$

Assuming that the conductivity is constant through the interface, the total electric potential at surface is (Fournier, 1989):

$$
\psi=\frac{C_{1}-C_{2}}{2 \pi} \iint_{S} H \frac{\mathbf{r} \cdot \mathbf{n}}{r^{3}} d s .
$$

This method was used to interpret the gradient observed in the central part of the survey, which may correspond to a fault, as slightly suggested by the EM survey.

The SP values observed in two profiles, acquired at two distinct times are shown in Fig. 6. The pattern of these curves are similar to those obtained in the limit of an aquifer (Fournier, 1989). Following this point of view the detected fault would be the upstream limit of the southwards aquifer.

The depth of the basement of the aquifer $(150 \mathrm{~m})$ was chosen based on the interpretation of the geological-log obtained from a well drilled close to the spring. There are not too much published values of $C$ in the literature. This coefficient depends on the conductivity of the fluid and on its dynamical viscosity. Dielectric constant and zeta potential at the rock/fluid interface are also parameters with influence on $C$. Ogilvy et al. (1969) showed that for natural waters small values of $C$ are expected. The conductivity of the waters in the area is significant (2100 to $3050 \mu \mathrm{S} / \mathrm{cm}$, Marques et al., 2000). This high conductivity of the water contributes to decrease the coupling coefficient. Using the equation presented by Fournier (1983), which give $C$ as function of the 


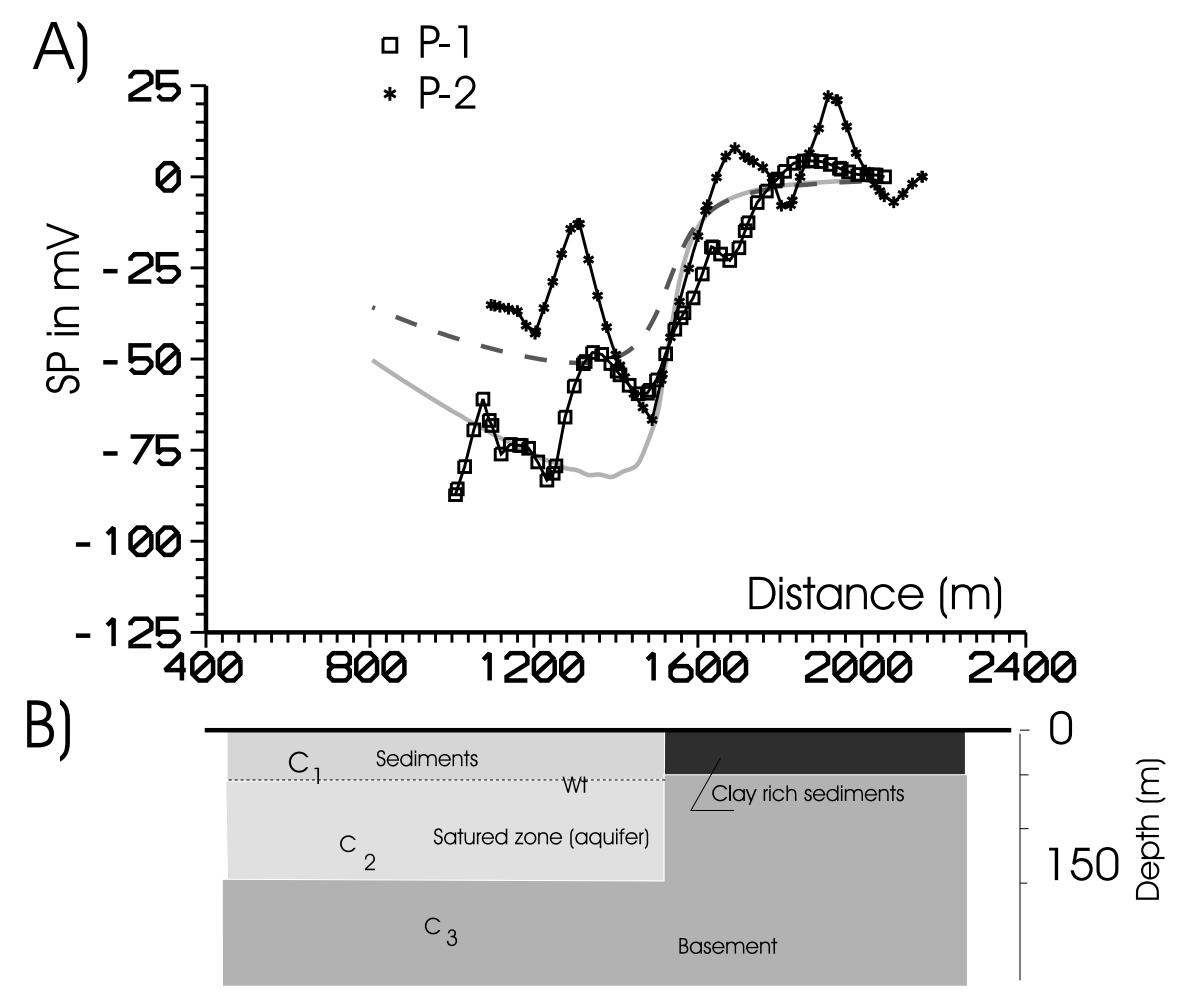

Fig. 6. A) SP profiles P-1 and P-2 (see Fig. 5, for location) and theoretical responses (solid and dashed lines) obtained from the model shown in B). Geoelectric model used in the calculation of the SP responses shown in A). Wt represents the water table; $C_{1}, C_{2}$ and $C_{3}$ are the electrokinetics coefficients.

water resistivity, $C=0.309 \rho_{w}^{0.91}(C$ in $\mathrm{mV} / \mathrm{m}$ and the water resistivity $\rho_{w}$ in ohm $\mathrm{m}$ ) one obtain $C$ ranging from 0.92 to $1.29 \mathrm{mV} / \mathrm{m}$. However, the high permeability of the rock increases the coefficient (Pozzi and Jouniaux, 1994). In this work the following values for the coupling coefficients were assumed; $C_{1}=0 \mathrm{mV} / \mathrm{m}$ in the desaturated zone (the SP potential produced in this zone can be neglected); $C_{2}=1.25$ $\mathrm{mV} / \mathrm{m}$ in the satured one and $C_{3}=1.50$ in the basement.

Figure 6 shows the responses calculated using the method proposed by Fournier (1989) and taken the values of $P / K=$ $5 \times 10^{-3}$ for the profile 1 (acquired at the end of the winter season) and equal to $3 \times 10^{-3}$ for the profile 2 acquired two months later. Here, $P$ is the efficient rainfall and $K$ the permeability. Comparing the theoretical SP anomaly with the observed one we can conclude that the main features of the data are well represented in the model response. There are two hypotheses to interpret the narrow anomaly located at co-ordinate $1500 \mathrm{~m}$, mainly in the profile 2 . This feature can be due to the influence of the water exploitation well located in neighbourhood of the profile or it is due to the effect of the water circulation in the NWW-SEE fault.

\section{Conclusions}

Electromagnetic and SP surveys were used in delineating the shallow structures associated to the main mineral water spring in Vilarelho da Raia area. According to isotopic data (Marques et al., 2000) the recharge area of the aquifer is located in Larouco Mountains (NW of the studied zone). During its long residence times (times in excess to 50 years are indicated by the low tritium levels (Marques et $a l ., 2000)$ ) and shallow circulation levels (as indicated by the low issue temperature of these waters), the waters were mineralised by water-gas-rock interactions in a low-temperature environment (coherent indications derive from the high $\mathrm{CO}_{2}$ content of these waters). The EW fault system that develops from the Larouco Mountain towards Vilarelho da Raia area might control the regional circulation of these waters, while local structures (mainly in NW-SE and NNE-SSW direction) create the necessary conditions for their ascent toward the basin generating a shallow aquifer.

The EM34 results allow the estimation, even in a preliminary way, of the porosity of the fractured massif, as well as, its protection from superficial pollution. The model indicates that the clay overburden is thin (except in the NE part of the survey) and seems not enough for a good protection of the aquifer.

There are some difficulties in the correlation of our EM34 model features with faults. Nevertheless the use of the SP method allow the detection and characterisation of the fault associated with the upflow of the water in the spring area.

Acknowledgments. Thanks are due to Xavier Garcia and Emin Ulugergerli for their comments and suggestions. This research was supported by the Praxis Project AQUATRANSFER No. 3/3.1/ CEG/2664/95.

\section{References}

Aires-Barros, L., J. M. Marques, and R. C. Graą, Elemental and isotopic geochemistry in the hydrothermal area of Chaves/Vila Pouca de Aguiar (Northern Portugal), Environmental Geology, 25(4), 232-238, 1995.

Aires-Barros, L., J. M. Marques, R. C. Graą, M. J. Matias, C. H. van der Weijden, R. Kreulen, and H. G. M. Eggenkamp, Hot and cold $\mathrm{CO}_{2}$-rich mineral waters in Chaves geothermal area (northern Portugal), Geothermics, 27(1), 89-107, 1998. 
Astier, J. L., Geofisica Aplicada a la Hidrogeologia, 2nd edition, Paraninfo, Madrid, 1982.

Fitterman, D. V., Electrokinetic and magnetic anomalies associated with dilatent regions in a layered earth, J. Geophys. Res., 83, 5924-5934, 1978.

Fournier, C., Méthodes geoelectriques appliquées à l'hydrogéologie en région volcanique (Chaîne des Puys, Massif Central Franạis). Développement de la méthode des potentiels spontanés en hydrogéologie. Thèse de 3eme cycle de Geologie, Université des Sciences et Techniques du Languedoc (Montpellier II), 1983.

Fournier, C., Spontaneous Potentials and resistivity surveys applied to hydrogeology in a volcanic area: case history of the Chaîne des Puys (Puyde-Dôme, France), Geophysical Prospecting, 37, 647-668, 1989.

Marques, J. M., F. A. Monteiro Santos, R. C. Graạ, R. Castro, L. AiresBarros, and L. A. Mendes-Victor, A Geochemical and geophysical approach to derive a conceptual circulation model of $\mathrm{CO}_{2}$-Rich mineral waters: a case study of Vilarelho da Raia (NE Portugal), Hydrogeology Journal, 9, 584-596, 2001.

McNeill, J. D., Electromagnetic terrain conductivity measurements at low induction numbers, Geonics Limited, Technical Note TN-6, 1980.

McNeill, J. D., Use of electromagnetic methods for groundwater studies, in Geotechnical and Environmental Geophysics, edited by S. Ward, Society of Exploration Geophysicists, Investigations in Geophysics no. 5, 191218, 1990.

Monteiro Santos, F. A., A. Dupis, A. R. Andrade Afonso, and L. A.
Mendes-Victor, Magnetotelluric observations over the Chaves geothermal field (NE Portugal)-preliminary results, Phys. Earth Planet. Inter., 91, 203-211, 1995.

Monteiro Santos, F. A., A. Dupis, A. R. Andrade Afonso, and L. A Mendes-Victor, An audiomagnetotelluric survey over the Chaves geothermal field (NE Portugal), Geothermics, 25(3), 389-406, 1996.

Monteiro Santos, F. A., H. Matias, and R. Gonalves, The use of EM343 surveys in cave detection, European Journal of Environmental and Engineering Geophysic, 6, 153-166, 2001.

Ogilvy, A. A., M. A. Ayed, and V. A. Bogolovsky, Geophysical studies of water leakage from reservoirs, Geophysical Prospecting, 28, 792-804, 1969.

Portugal Ferreira, M., A. Sousa Oliveira, and A. N. Trota, Chaves geothermal pole. Geological Survey, I and II. Joule I Program, DGXII, CEE. UTAD (Universidade de Trás-os-Montes e Alto Douro) internal report 1992.

Pozzi, J. P. and L. Jouniaux, Effets électriques des circulations de fluides dans les roches sédimentaires et prévision des séismes, C. R. Acad. Sci. Paris, t. 318, série II, 73-77, 1994.

Sasaki, Y., Two-dimensional joint inversion of magnetotelluric and dipoledipole resistivity data, Geophysics, 54, 254-262, 1989.

F. A. Monteiro Santos (e-mail: dfams@fc.ul.pt), E. P. Almeida, R. Castro, R. Nolasco, and L. Mendes-Victor 